\title{
Presepsin (sCD14-ST): could it be a novel marker for the diagnosis of ST elevation myocardial infarction?
}

\author{
Fatma Nihan Turhan Caglar ${ }^{1}$, Nilgun Isiksacan², Ismail Biyik³ ${ }^{3}$ Selcuk Opan¹, Hulya Cebe ${ }^{1}$, \\ Ibrahim Faruk Akturk ${ }^{1}$
}

\author{
${ }^{1}$ Department of Cardiology, Bakirkoy Dr. Sadi Konuk Education and Research Hospital, \\ Istanbul, Turkey \\ ${ }^{2}$ Department of Biochemistry, Bakirkoy Dr. Sadi Konuk Education and Research \\ Hospital, Istanbul, Turkey \\ ${ }^{3}$ Department of Cardiology, Usak University Education and Research Hospital, Usak, \\ Turkey
}

Submitted: 3 March 2017

Accepted: 12 March 2017

Arch Med Sci Atheroscler Dis 2017; 2: e3-e8

DOI: https://doi.org/10.5114/amsad.2017.66827

Copyright (c) 2017 Termedia \& Banach

\section{Abstract}

Introduction: Acute myocardial infarction (AMI) could be considered to be a state of inflammation. Many inflammatory markers have been evaluated in the AMI setting so far. Presepsin (PSP) is a novel biomarker for diagnosis and prognosis of systemic inflammation that has not been studied in the AMI setting to date. In this study, we aimed to examine serum PSP levels in patients with acute ST elevation myocardial infarction (STEMI).

Material and methods: Forty-eight patients with STEMI and fifty healthy controls without coronary artery disease, verified by coronary angiography, were included in the study. Together with routine laboratory tests needed for STEMI, plasma concentrations of PSP were measured in peripheral venous blood samples of the participants.

Results: Plasma PSP and troponin levels were significantly higher in patients with STEMI than controls $(1988.89 \pm 3101.55$ vs. $914.22 \pm 911.35 \mathrm{pg} / \mathrm{ml}$, $p=0.001$ and $3.46 \pm 3.39$ vs. $0.08 \pm 0.43 \mathrm{ng} / \mathrm{ml}, p=0.001$, respectively). The cut-off value for PSP of $447 \mathrm{pg} / \mathrm{ml}$ was found to detect STEMI with $87.5 \%$ sensitivity, $44 \%$ specificity, $60 \%$ positive predictive value and $78.5 \%$ negative predictive value.

Conclusions: In this study, PSP levels were found to be significantly elevated in patients with STEMI together with high-sensitivity troponins. The PSP may be a new marker for AMI detection. Large scale studies are needed to reveal the importance of PSP in the diagnosis and prognosis of AMI.

Key words: myocardial infarction, presepsin, inflammation, atherosclerosis.

\author{
Corresponding author: \\ Ismail Biyik \\ Department of Cardiology \\ Usak University Education \\ and Research Hospital \\ 64100 Usak, Turkey \\ Fax: +90 5424173209 \\ E-mail: ismailbiyikmd@ \\ yahoo.com
}

\section{Introduction}

Coronary artery disease (CAD) is still the leading cause of death worldwide [1]. The role of inflammation in the process of atherosclerosis from fatty streak formation to plaque erosion, rupture and thrombosis is well documented [1]. Inflammatory biochemical markers facilitate early and accurate diagnosis of acute myocardial infarction (AMI) and help to predict prognosis [2]. Over the past decade, the role of T-lymphocytes, monocytes, macrophages and platelets in atherosclerosis has been broadly studied [3]. C-reactive protein (CRP), interleukin-6 (IL-6), 
tumor necrosis factor- $\alpha$ (TNF- $\alpha$ ), intercellular adhesion molecule-1 (ICAM-1), CD4OL and P-selectin are some of the mostly studied inflammatory markers in patients with AMI [1]. Alongside these well-studied inflammatory markers, there is enthusiasm in the research of novel markers on the early detection of AMI and their prognostic importance. Monocytes, macrophages and neutrophils express a cluster of differentiation (CD) surface glycoprotein named CD14 [4]. CD14 forms a circulating soluble subtype after being activated by plasma proteases, which is named SCD14-ST, also known as presepsin (PSP) [4]. Several clinical studies have suggested that PSP is an acute phase reactant similar to CRP [5]. Although the diagnostic power, prognostic value and mortality predictive capacity of PSP are widely evaluated and accepted in sepsis, no publications about the association between PSP and atherosclerosis are available in the literature [2].

In this study, we aimed to examine plasma PSP levels in patients with acute ST elevation myocardial infarction (STEMI).

\section{Material and methods}

\section{Study population}

This observational comparative study was conducted in a tertiary referral center from August 2014 to December 2014. Forty-eight patients diagnosed with acute STEMI undergoing primary percutaneous coronary intervention within $6 \mathrm{~h}$ of symptom onset were included in the patient group and fifty healthy patients without coronary artery disease as verified by coronary angiography were enrolled in the control group. The diagnosis of AMI was made according to related guideline, so symptoms of myocardial ischemia and ST segment elevation $\geq 1 \mathrm{~mm}$ in two contiguous electrocardiographic leads or new onset of complete left bundle-branch block was defined as ST elevation myocardial infarction [6]. Patients with known CAD, estimated glomerular filtration rate $(e G F R)<60 \mathrm{ml} / \mathrm{min}$, serious valvular disease, uncontrolled hypertension, heart failure, serious hepatic failure, acute or chronic infection, fever, muscle aches, headache, receiving antibiotics therapy, immunoproliferative disease, rheumatic disease, malignancy, osteoporosis and older than 75 years old were excluded. The study protocol was approved by the local ethics committee of the institution and written informed consent was taken from all patients for participation. The study process was rigorously conducted in accordance with the Declaration of Helsinki, Good Clinical Practice (GCP) and International Conference on Harmonization (ICH) guidelines.

\section{Laboratory measurements}

Blood samples for PSP and other measurements were drawn as soon as the diagnosis of AMI was made in the patient group and just after randomization from the control group. All of the laboratory data including high-sensitivity cardiac troponin-T (cTn-T) and high-sensitivity CRP (hsCRP) were documented. Blood samples for PSP measurement were obtained by vein puncture into ethylene diamine tetra acetic acid (EDTA) blood collection tubes without additives and immediately centrifuged at $2500 \mathrm{rpm}$ for $10 \mathrm{~min}$. The serum was collected after centrifugation and stored at $-80^{\circ} \mathrm{C}$ until analysis up to 6 months. The samples were thawed out once. All the assays were performed on serum according to the manufacturer's recommendations with the Pathfast immunoassay analytical system (Progen Biotechnik GmbH, Germany and Mitsubishi Chemical Medience Corporation, Japan) using plasma from EDTA tubes. cTn-T measurements were performed from the obtained plasma samples with the device of Cobas e411 (Roche High Sensitive Troponin T, Hoffman-La Roche Ltd, Basel, Switzerland) with the method of chemiluminescence.

\section{Statistical analysis}

The Number Cruncher Statistical system (NCSS) (Kaysville, Utah, USA 2007) program was used for statistical analysis. Study data were analyzed using descriptive statistical methods. Normally distributed quantitative data were analyzed by Student's $t$ test, and non-normally distributed data were analyzed by the Mann-Whitney $U$ test. Qualitative data were analyzed by Yates' continuity correction test. Diagnostic screening tests such as sensitivity, specificity, positive predictive value and negative predictive value and the receiver operating characteristic (ROC) curve test were used for determining PSP and CTn-T cut-off values. Spearman's rank correlation was used to test the association of PSP with other laboratory parameters. $P$-values (two-tailed) lower than 0.01 with a $99 \%$ confidence interval and 0.05 with a $95 \%$ confidence interval were considered as statistically significant.

\section{Results}

Baseline characteristics and laboratory findings are shown in Table I. Mean age, body mass index (BMI), smoking and history of hypertension were similar between groups. CTn-T levels were significantly higher in the STEMI group than controls, as expected ( $3.46 \pm 3.39$ vs. $0.08 \pm 0.43 \mathrm{ng}$ / $\mathrm{ml}$, respectively, $p=0.001$ ). The PSP levels were significantly higher in the STEMI group than controls (1988.89 \pm 3101.55 vs. $914.22 \pm 911.35$ pg/ 
Table I. Demographic features and laboratory findings of STEMI and controls

\begin{tabular}{|c|c|c|c|c|}
\hline \multicolumn{2}{|l|}{ Parameter } & \multirow{2}{*}{$\begin{array}{c}\text { Controls }(n=50) \\
58.58 \pm 8.52 \\
36-76(59)\end{array}$} & \multirow{2}{*}{$\begin{array}{c}\text { STEMI }(n=48) \\
59.19 \pm 11.62 \\
42-89(58.5)\end{array}$} & \multirow{2}{*}{$\begin{array}{c}P \text {-value } \\
{ }^{a} 0.873^{*}\end{array}$} \\
\hline Age [years] & $\begin{array}{c}\text { Mean } \pm \text { SD } \\
\text { Min.-max. (median) }\end{array}$ & & & \\
\hline \multirow[t]{2}{*}{ Gender, $n(\%)$} & Male & $16(32.0)$ & $35(72.9)$ & \multirow[t]{2}{*}{${ }^{b} 0.001^{* *}$} \\
\hline & Female & $34(68.0)$ & $13(27.1)$ & \\
\hline BMI $\left[\mathrm{kg} / \mathrm{m}^{2}\right]$ & $\begin{array}{c}\text { Mean } \pm \text { SD } \\
\text { Min.-max. (median) }\end{array}$ & $\begin{array}{l}28.38 \pm 3.27 \\
20-36(29)\end{array}$ & $\begin{array}{l}27.33 \pm 3.18 \\
21-33(27.5)\end{array}$ & b0.112* \\
\hline \multirow[t]{2}{*}{ Smoking, $n(\%)$} & No & $26(52.0)$ & $16(33.3)$ & \multirow[t]{2}{*}{$0.096^{*}$} \\
\hline & Yes & $24(48.0)$ & $32(66.7)$ & \\
\hline \multirow[t]{2}{*}{ Hypertension, $n$ (\%) } & No & $28(56.0)$ & $28(58.3)$ & \multirow[t]{2}{*}{${ }^{c} 0.977^{\star}$} \\
\hline & Yes & $22(44.0)$ & $20(41.7)$ & \\
\hline \multirow[t]{2}{*}{ Diabetes, $n$ (\%) } & No & $40(80.0)$ & $37(77.1)$ & \multirow[t]{2}{*}{${ }^{\prime} 0.916^{*}$} \\
\hline & Yes & $10(20.0)$ & $11(22.9)$ & \\
\hline $\mathrm{cTn}-\mathrm{T}[\mathrm{ng} / \mathrm{ml}]$ & $\begin{array}{c}\text { Mean } \pm \text { SD } \\
\text { Min.-max. (median) }\end{array}$ & $\begin{array}{c}0.08 \pm 0.43 \\
0.002-2.98(0.007)\end{array}$ & $\begin{array}{c}3.46 \pm 3.39 \\
0.006-13.80(2.2)\end{array}$ & ${ }^{a} 0.001^{\star *}$ \\
\hline Presepsin [pg/ml] & $\begin{array}{c}\text { Mean } \pm \text { SD } \\
\text { Min.-max. (median) }\end{array}$ & $\begin{array}{c}914.22 \pm 911.35 \\
111-4000(541.5)\end{array}$ & $\begin{array}{l}1988.89 \pm 3101.55 \\
243-19137(1086)\end{array}$ & ${ }^{\mathrm{a}} 0.001^{* *}$ \\
\hline $\mathrm{Hs}-\mathrm{CRP}[\mathrm{mg} / \mathrm{l}]$ & $\begin{array}{c}\text { Mean } \pm \text { SD } \\
\text { Min.-max. (median) }\end{array}$ & $\begin{array}{c}5.70 \pm 11.90 \\
0.04-68.70(2.8)\end{array}$ & $\begin{array}{c}4.43 \pm 8.22 \\
0.09-33.66(1.5)\end{array}$ & ${ }^{\mathrm{a}} 0.239^{\star}$ \\
\hline Creatinine $[\mathrm{mg} / \mathrm{dl}]$ & $\begin{array}{c}\text { Mean } \pm \text { SD } \\
\text { Min.-max. (median) }\end{array}$ & $\begin{array}{c}0.78 \pm 0.17 \\
0.42-1.03(0.68)\end{array}$ & $\begin{array}{c}0.87 \pm 0.25 \\
0.41-1.13(0.74)\end{array}$ & ${ }^{\mathrm{a}} 0.056^{\star *}$ \\
\hline WBC $\left[\times 10^{9} / 1\right]$ & $\begin{array}{c}\text { Mean } \pm \text { SD } \\
\text { Min.-max. (median) }\end{array}$ & $\begin{array}{c}8.92 \pm 3.21 \\
5.00-17.60(8.20)\end{array}$ & $\begin{array}{c}12.49 \pm 2.89 \\
3.03-18.00(12.6)\end{array}$ & ${ }^{\mathrm{a}} 0.001^{\star *}$ \\
\hline
\end{tabular}

aMann-Whitney U Test, ${ }^{b}$ Student $t$ test, ${ }^{c}$ Yates continuity correction test, ${ }^{*} p<0.05,{ }^{\star *} p<0.01 ;$ SD - standard deviation, cTn-T - cardiac troponin T, BMI - body mass index, CVA - cerebrovascular accident, WBC - white blood cells.

$\mathrm{ml}$, respectively, $p=0.001$, Figure 1 ). White blood cells count was higher in patients with STEMI than controls $\left(8.92 \pm 3.21 \times 10^{3}\right.$ vs. $12.49 \pm 2.89 \times$ $10^{3}$, respectively, $\left.p=0.001\right)$. Diagnostic screening tests and ROC curve analysis for determining cut-off for cTn-T and PSP are presented in Table II. The cut-off value for cTn-T was $0.017 \mathrm{ng} / \mathrm{ml}$ to detect STEMI with $97.9 \%$ sensitivity, $92.0 \%$ specificity, $92.1 \%$ positive predictive value and $97.8 \%$ negative predictive value, and the cutoff value for PSP was $447 \mathrm{pg} / \mathrm{ml}$ to detect STEMI with $87.5 \%$ sensitivity, $44 \%$ specificity, $60 \%$ positive predictive value and $78.5 \%$ negative predictive value. The diagnostic value of PSP levels $(A \cup C=0.69)$ to diag-

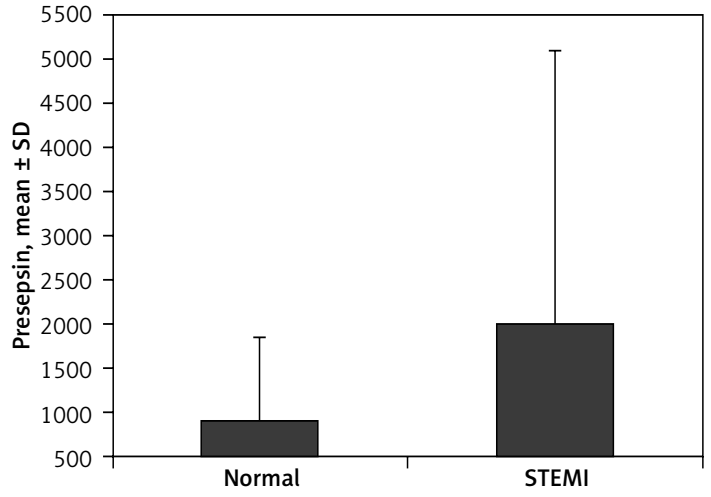

Figure 1. Presepsin values between STEMI and controls

Table II. Diagnostic screening tests and ROC curve analysis for troponin and presepsin

\begin{tabular}{|c|c|c|c|c|c|c|c|c|}
\hline \multirow[t]{2}{*}{ Parameter } & \multicolumn{5}{|c|}{ Diagnostic scan } & \multicolumn{2}{|c|}{ ROC curve } & \multirow[t]{2}{*}{$P$-value } \\
\hline & Cut-off & Sensitivity & Specificity & $\begin{array}{c}\text { Positive } \\
\text { predictive } \\
\text { value }\end{array}$ & $\begin{array}{c}\text { Negative } \\
\text { predictive } \\
\text { value }\end{array}$ & AUC & $\begin{array}{l}\text { Confidence } \\
\text { interval } 95 \%\end{array}$ & \\
\hline cTn-T & $\geq 0.017$ & 97.92 & 92.00 & 92.16 & 97.87 & 0.973 & $0.940-1.000$ & 0.001 \\
\hline Presepsin & $\geq 447$ & 87.50 & 44.00 & 60.00 & 78.57 & 0.692 & $0.587-0.797$ & 0.001 \\
\hline
\end{tabular}

$R O C$ - receiver operating characteristic, AUC - area under the curve, $C T n-T$ - cardiac troponin $T$. 


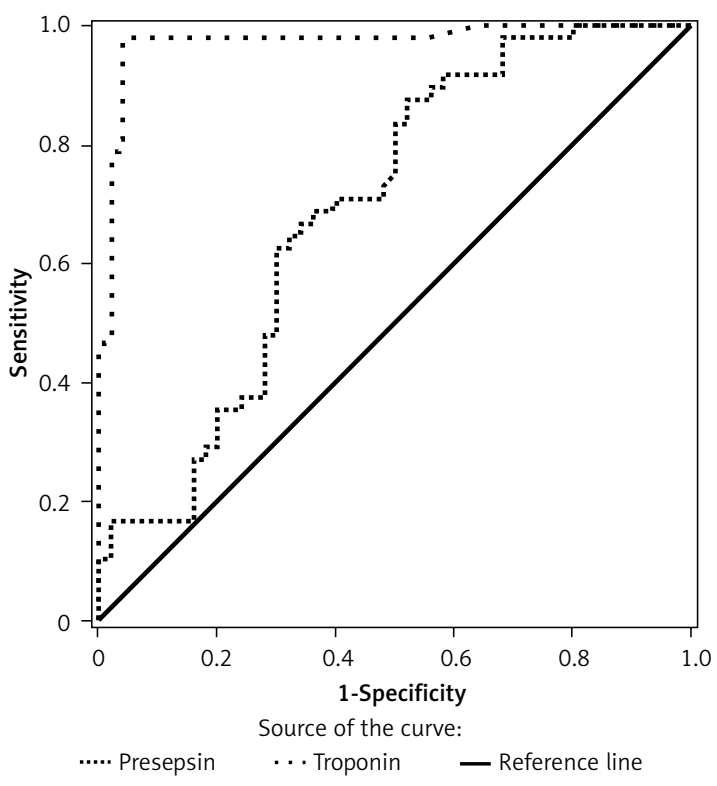

Figure 2. ROC curve analysis of presepsin and troponin

Table III. Univariate correlations of presepsin with laboratory parameters

\begin{tabular}{|llll|}
\hline Parameter & & Normal & STEMI \\
\hline CTn-T & $r$ & 0.061 & 0.133 \\
\cline { 2 - 4 } & $p$ & 0.673 & 0.368 \\
\hline Creatinine & $r$ & 0.046 & 0.157 \\
\cline { 2 - 4 } & $p$ & 0.750 & 0.286 \\
\hline WBC & $r$ & 0.043 & 0.180 \\
\cline { 2 - 4 } & $p$ & 0.768 & 0.221 \\
\hline Hs-CRP & $r$ & 0.124 & 0.144 \\
\cline { 2 - 4 } & $p$ & 0.493 & 0.557 \\
\hline
\end{tabular}

$r$-Spearman's correlation coefficient, $p-p$-value, $c T n-T$ - cardiac troponin T, WBC - white blood cells, hs-CRP - high sensitivity $C$-reactive protein, STEMI - ST elevation myocardial infarction.

nose STEMI was statistically lower than troponin (AUC $=0.97, p<0.001$ ) (Figure 2). The PSP levels were not correlated with CTn-T, creatinine, hsCRP or WBC (Table III).

\section{Discussion}

The present study suggested that plasma PSP levels are significantly higher in STEMI patients compared to controls, and the cut-off value of PSP to detect STEMI is $447 \mathrm{pg} / \mathrm{ml}$, and it has $87.5 \%$ sensitivity, $44 \%$ specificity, $60 \%$ positive predictive value and $78.5 \%$ negative predictive value. However, the diagnostic power of PSP to diagnose STEMI was found to be statistically lower than that of cTn-T. Acute inflammation due to diminished oxygen supply to the myocardium and related myocyte necrosis during $\mathrm{AMI}$ are mostly controlled by monocytes and macrophages [2, 7, $8]$. Also, neutrophils play a crucial role in myocardial reperfusion injury and positive remodeling of the myocardial tissue after AMI, and this process is also mediated in part by monocytes and macrophages $[8,9]$. Although WBC count, hsCRP, polymorphonuclear leukocytes and interleukin-6 (IL-6) have been widely investigated for this purpose and have shown promising results, they are influenced by many different factors and the results are still controversial [1,7,9-11]. In this context, PSP may be a promising biomarker in scientific research of $\mathrm{AMI}$ pathogenesis and may reflect vascular inflammation during AMI [2]. The PSP was first found in 2004 [12]. Previous studies demonstrated the diagnostic capacity of PSP with high sensitivity and specificity for the diagnosis of diseases accompanied by systemic inflammation such as sepsis [4, 13]. Our study is the first to evaluate serum PSP levels in the AMI setting. Furthermore, we also assessed other well-known inflammatory biomarkers related to atherosclerosis such as WBC count and serum hs-CRP levels. Although hs-CRP levels were similar among groups, WBC count was significantly higher in STEMI patients compared to controls. Similarly, previous reports have demonstrated increased levels of WBC count in AMI patients $[9,14]$. In spite of the fact that how PSP is produced in the body is not well known, it normally exists for a certain amount in the plasma of healthy subjects and increases in response to inflammation $[13,15]$. The present study revealed a median value of PSP concentration of $541 \mathrm{pg} / \mathrm{ml}$, ranging between 111 and 4000 $\mathrm{pg} / \mathrm{ml}$ in the plasma of healthy subjects. Previous studies have demonstrated different plasma PSP concentrations and cut-off levels for both healthy subjects and various patient groups [15]. Chenevier-Gobeaux et al. compared PSP concentrations in patients admitted to the emergency room without acute infection or acute disorders and healthy volunteers, and found a median PSP value of 202 $\mathrm{pg} / \mathrm{ml}$ in healthy volunteers, whereas the median PSP concentration was $750 \mathrm{pg} / \mathrm{ml}$ in the patient population, and they also reported that presepsin concentrations increase with age and kidney dysfunction [16]. Endo et al. suggested $600 \mathrm{pg} / \mathrm{ml}$ as the cut-off value for bacterial and non-bacterial infectious diseases [17]. Shozushima et al. obtained a median PSP level of $294 \mathrm{pg} / \mathrm{ml}$ in the plasma of healthy subjects and determined $415 \mathrm{pg} / \mathrm{ml}$ as the cut-off value for inflammatory diseases with 0.80 sensitivity and 0.81 specificity [18]. The cutoff value of PSP to diagnose STEMI was $447 \mathrm{pg} /$ $\mathrm{ml}$ with 0.87 sensitivity and 0.44 specificity in the present study. The wide range of PSP levels among studies may be due to the selection bias of the subjects $[12,15]$. Accordingly, plasma PSP 
concentrations are known to increase in cases of renal insufficiency and in patients over 70 years $[16,19]$. Therefore we excluded patients with renal insufficiency and those over 75 years old, and serum creatinine levels and mean age were similar between groups in our study. Moreover, substantial heterogeneity due to measuring PSP by different instruments has been demonstrated by a meta-analysis [12]. We measured PSP levels with the chemiluminescent enzyme immunoassay method, which is the method used most frequently in other studies. Early detection and timely treatment of $\mathrm{AMI}$ are of great importance to prevent complications [20]. Traditionally used troponin levels allow diagnosis of STEMI with sufficient sensitivity and specificity [20]. The results obtained in the present study are consistent with earlier reports, and CTn-T showed $97.9 \%$ sensitivity and $92 \%$ specificity for the diagnosis of STEMI, but the diagnostic value of PSP levels to diagnose STEMI was lower than $\mathrm{CTn}-\mathrm{T}$ (AUC $=0.69$ vs. $\mathrm{AUC}=97, p=0.001$ ). However, in our opinion, PSP cut-off values may still allow one to recognize or exclude patients with and without AMI as accurately as the traditional cardiac marker, troponin, with $87 \%$ clinical sensitivity and $78.5 \%$ negative predictive values [15]. The PSP measurement takes only $21 \mathrm{~min}$ with the chemiluminescent enzyme immunoassay method, which may allow STEMI to be diagnosed as fast as troponin [13]. Studies also evaluated PSP for risk prediction in severe inflammatory diseases and found it convenient [13]. Behnes et al. assessed PSP in sepsis and septic shock groups, and observed higher PSP concentrations in patients who died on the first day than survivors and a decline in PSP levels by the $7^{\text {th }}$ day in survivors, and PSP levels were correlated with sepsis scoring systems [21]. Moreover, PSP was better than procalcitonin for the prediction of prognosis in their study [21]. Liu et al. observed an increase in PSP levels among patients with sepsis, severe sepsis, the septic shock group and the death group, and diagnostic sensitivity of PSP was $82 \%$ for severe sepsis and $86 \%$ for septic shock. In predicting the risk of death, PSP was superior to IL-6, CRP and procalcitonin [22]. Olad et al. evaluated PSP levels in patients with chemotherapy-induced neutropenia and concluded that PSP levels are well correlated with the severity of infections in this group of patients [23]. Behnes et al. not only demonstrated the diagnostic capacity of PSP in recognizing the severity of sepsis, but also revealed the prognostic power of PSP, assessed during the first week of intensive care treatment, in predicting 30 days and 6 months all-cause mortality in patients with severe sepsis and septic shock [21]. They also reported significant correlations with PSP and some of the sepsis scoring systems such as APACHE II (Acute Physiology and Chronic Health Evaluation II) and SOFA (Sepsis-related Organ Failure Assessment score) [21]. All of the above studies suggest that higher PSP levels are associated with adverse outcomes and subsequent mortality in patients with severe inflammation. According to the present study, PSP levels in patients with STEMI are not correlated with WBC count or serum hs-CRP levels. Similarly, Olad et al. also observed that PSP levels were independent from WBC count in their study conducted on patients with chemotherapy-induced severe neutropenia [23].

The present study has some limitations. The main limitations of our study were its single-centered basis and relatively small patient population size. Biomarker follow-up during $\mathrm{AMI}$ is of fundamental clinical importance. We were able to measure PSP once, so we may have missed the biological intra-individual variation of PSP in the AMI setting. Besides the above limitations, according to our knowledge, the strength of the present study comes is that it is the first in terms of evaluating serum PSP levels in AMI patients. Future comprehensive studies with large patient population groups may provide more precise results.

In conclusion, in this study, PSP levels were found to be significantly elevated in patients with STEMI together with high-sensitivity troponins. The results of this preliminary study suggest that PSP may be a promising new biomarker for AMI detection. Large scale and comprehensive studies are needed to reveal the importance of PSP in the diagnosis and the prediction of prognosis of AMI.

\section{Conflict of interest}

The authors declare no conflict of interest.

\section{References}

1. Wilson AM, Ryan MC, Boyle AJ. The novel role of C-reactive protein in cardiovascular disease: risk marker or pathogen. Int J Cardiol 2006; 106: 291-7.

2. Popov D, Plyushch M, Ovseenko S, Abramyan M, Podshchekoldina O, Yaroustovsky M. Prognostic value of SCD14-ST (presepsin) in cardiac surgery. Kardiochir Torakochir Pol 2015; 12: 30-6.

3. Dorweiler B, Torzewski M, Dahm M, Kirkpatrick CJ, Lackner K, Vahl C. Subendothelial infiltration of neutrophil granulocytes and liberation of matrix-destabilizing enzymes in an experimental model of human neo-intima. Thromb Haemost 2008; 99: 373-81.

4. Ovayolu A, Özdamar Ö, Gün I, et al. Can blood or follicular fluid levels of presepsin predict reproductive outcomes in ART: a preliminary study. Int J Clin Exp Med 2015; 8: 7983-8.

5. Aalto H, Takala A, Kautiainen H, Siitonen S, Repo H. Monocyte CD14 and soluble CD14 in predicting mortality of patients with severe community acquired infection. Scand I Infect Dis 2007; 39: 596-603.

6. Thygesen K, Alpert JS, Jaffe AS; Joint ESC/ACCF/AHA/ WHF Task Force for the Universal Definition of Myocar- 
dial Infarction. Third universal definition of myocardial infarction. Circulation 2012; 126: 2020-35.

7. Quinn K, Henriques M, Parker T, Slutsky AS, Zhang H. Human neutrophil peptides: a novel potential mediator of inflammatory cardiovascular diseases. Am J Physiol Heart Circ Physiol 2008; 295: 1817-24.

8. Arai M, Lefer DJ, So T, DiPaula A, Aversano T, Becker LC. An anti-CD18 antibody limits infarct size and preserves left ventricular function in dogs with ischemia and 48 hour reperfusion. J Am Coll Cardiol 1996; 27: 1278-85.

9. Menon V, Lessard D, Yarzebski J, Furman MI, Gore JM, Goldberg RJ. Leukocytosis and adverse hospital outcomes after acute myocardial infarction. Am J Cardiol 2003; 92: 368-72.

10. Yip HK, Hang CL, Fang CY, et al. Level of high-sensitivity C-reactive protein is predictive of 30 day outcomes in patients with acute myocardial infarction undergoing primary coronary intervention. Chest 2005; 127: 803-8.

11. Ridker PM. High-sensitivity C-reactive protein: potential adjunct for global risk assessment in the primary prevention of cardiovascular disease. Circulation 2001; 103: 1813-8.

12. Zheng Z, Jiang L, Ye L, Gao Y, Tang L, Zhang M. The accuracy of presepsin for the diagnosis of sepsis from SIRS: a systematic review and meta-analysis. Ann Intensive Care 2015; 5: 48.

13. Zou Q, Wen W, Zhang X. Presepsin as a novel sepsis biomarker. World J Emerg Med 2014; 5: 16-9.

14. Dharma S, Hapsari R, Siswanto BB, van der Laarse A, Jukema JW. Blood leukocyte count on admission predicts cardiovascular events in patients with acute nonST elevation myocardial infarction. Int J Angiol 2015; 24 : 127-32.

15. Giavarina D, Carta M. Determination of reference interval for presepsin, an early marker for sepsis. Biochem Med (Zagreb) 2015; 25: 64-8.

16. Chenevier-Gobeaux C, Trabattoni E, Roelens M, Borderie D, Claessens YE. Presepsin (SCD14-ST) in emergency department: the need for adapted threshold values? Clin Chim Acta 2014; 427: 34-6.

17. Endo S, Suzuki Y, Takahashi G, et al. Usefulness of prese$p s i n$ in the diagnosis of sepsis in a multicenter prospective study. J Infect Chemother 2012; 18: 891-7.

18. Shozushima T, Takahashi G, Matsumoto N, Kojika M, OkamuraY, Endo S. Usefulness of presepsin (sCD14-ST) measurements as a marker for the diagnosis and severity of sepsis that satisfied diagnostic criteria of systemic inflammatory response syndrome. I Infect Chemother 2011; 17: 764-9.

19. Honore PM, Jacobs R, Hendrickx I, De Waele E, Van Gorp V, Spapen HD. Presepsin and sepsis-induced acute kidney injury treated with continuous renal replacement therapy: will another promising biomarker bite the dust? Crit Care 2015; 19: 428.

20. Christenson RH, Duh SH. Evidence based approach to practice guides and decision thresholds for cardiac markers. Scand J Clin Lab Invest (Suppl) 1999; 230: 90 102.

21. Behnes M, Bertsch T, Lepiorz D, et al. Diagnostic and prognostic utility of soluble CD 14 subtype (presepsin) for severe sepsis and septic shock during the first week of intensive care treatment. Crit Care 2014; 18: 507.

22. Liu B, Chen YX, Yin Q, Zhao YZ, Li CS. Diagnostic value and prognostic evaluation of Presepsin for sepsis in an emergency department. Crit Care 2013; 17: R244.
23. Olad E, Sedighi I, Mehrvar A, et al. Presepsin (scd14) as a marker of serious bacterial infections in chemotherapy induced severe neutropenia. Iran J Pediatr 2014; 24 715-22. 